\title{
MicroRNA-101 modulates cisplatin chemoresistance in liver cancer cells via the DNA-PKes signaling pathway
}

\author{
ZONGTAO CHAI $^{*}$, XIAOLAN YIN ${ }^{2 *}$, JIN CHEN $^{2 *}$, JIE SHI $^{1}$, JUXIAN SUN $^{1}$, \\ CHANG LIU ${ }^{1}$, FENG LIU ${ }^{2}$ and SHUQUN CHENG ${ }^{1}$ \\ ${ }^{1}$ Department of Hepatic Surgery VI, Eastern Hepatobiliary Surgery Hospital; ${ }^{2}$ Precision Medical Center, \\ Shanghai Hospital, Second Military Medical University, Shanghai 200433, P.R. China
}

Received May 19, 2018; Accepted June 5, 2019

DOI: $10.3892 / 01.2019 .10674$

\begin{abstract}
Due to the high incidence of liver cancer, chemoradiotherapy and prognosis of liver cancer are a primary focus of medical research. microRNAs (miRNAs/miRs) serve crucial roles in resistance to chemotherapy and radiotherapy. The aim of the present study was to investigate the effects of miR-101 on the chemotherapeutic efficacy of cisplatin (CDDP) in liver cancer. First, human liver cancer cells (HepG2) were transfected with a miR-101 mimic or miR-101 inhibitor to bidirectionally regulate the expression of miR-101. Cell proliferation, apoptosis, intracellular reactive oxygen species and comet assay results indicated that the upregulation of miR-101 sensitized HepG2 cells to CDDP, and downregulation of miR-101 reduced chemosensitivity. A xenograft mouse model further confirmed that miR-101 overexpression increased CDDP sensitivity in liver cancer. Luciferase reporter and western blotting assays demonstrated that transfection of the miR-101 mimic markedly reduced activity of the DNA-dependent protein kinase catalytic subunit/protein kinase $\mathrm{B} / \mathrm{mammalian}$ target of rapamycin (DNA-PKcs/Akt/mTOR) pathway and increased expression of apoptotic protein caspase 3 , which is induced by CDDP treatment. By contrast, miR-101 inhibitors partially reversed these changes. Moreover, the miR-101 mimic suppressed activity of the nuclear factor $-\kappa \mathrm{B}(\mathrm{NF}-\kappa \mathrm{B})$ pathway, leading to increased susceptibility of HepG2 cells to chemotherapeutic agents. In conclusion, miR-101 overexpression augmented cytotoxicity and reduced chemoresistance to CDDP in HepG2 cells, and this was associated with negative regulation of DNA-PKcs/Akt/NF- $\kappa \mathrm{B}$ signaling.
\end{abstract}

Correspondence to: Dr Shuqun Cheng, Department of Hepatic Surgery VI, Eastern Hepatobiliary Surgery Hospital, Second Military Medical University, 225 Shanghai Road, Yangpu, Shanghai 200433, P.R. China

E-mail: chengshuqun@aliyun.com

*Contributed equally

Key words: microRNA-101, chemoresistance, cisplatin, liver cancer, DNA-dependent protein kinase catalytic subunit, protein kinase B

\section{Introduction}

Liver cancer is the third leading cause of cancer-related mortality, particularly in developing Asian countries, where the incidence has increased in recent years (1). Globally, approximately 630,000 new cases of liver cancer occur annually, and more than half of these new cases occur in China (2). Currently, systemic chemotherapy serves an important role in the treatment of advanced liver cancer and in therapy for liver cancer patients with extensive disease or with poor liver function $(3,4)$. Cisplatin (CDDP) is one of the most commonly used chemotherapeutic agents for advanced liver cancer and in postoperative patients when combined with intra-arterial chemotherapy (5). Unfortunately, the curative efficacy of CDDP may be limited due to intrinsic or acquired chemoresistance (6).

DNA double-strand break (DSB) repair is an important mechanism closely related to the development of chemoresistance (7). DNA-dependent protein kinase catalytic subunit (DNA-PKcs) is involved in nonhomologous end joining (NHEJ) to repair DSBs (8). DNA-PKcs mediates a variety of cellular responses via phosphorylation of various downstream targets in the DNA-PKcs signaling pathway (9). DNA-PKcs could promote activation of the mitogen-activated protein kinase

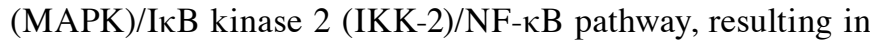
increased cell survival in murine embryonic fibroblasts treated with anthracycline doxorubicin chemotherapeutic agent (9). Elliott et al (10) reported that downregulation of DNA-PKcs sensitized chronic lymphocytic leukemia cells to chemotherapy treatment, while upregulation of DNA-PKcs was associated with chemoresistance and shorter survival time. Chemosensitivity was enhanced in multidrug-resistant human leukemia CEM cells in response to inhibition of DNA-PKcs through combined treatment with the DNA-PKcs inhibitor wortmannin (11). These results suggest that the DNA-PKcs signaling pathway is closely associated with development of chemoresistance.

MicroRNAs (miRNAs/miRs) are an important class of endogenous small noncoding RNAs that are typically approximately 22 nucleotides in length and bind to the 3'-untranslated region (UTR) of target $m$ RNAs, leading to the degradation of the mRNA or blocking translation (12). Dysregulation of miRNAs is also involved in the development of chemoresistance and radioresistance to therapy. MicroRNA-101 (miR-101) has been 
shown to efficiently sensitize tumor cells to radiation in vitro and in vivo through degradation of DNA-PKes via binding to the 3'-UTR of DNA-PKcs in tumor cells (13). It has been reported that miR-101 selectively targets and downregulates DNA-PKcs, mediating sensitivity of pancreatic cancer cells to gemcitabine (14). In addition, Chang et al (15) found that miR-101 sensitized osteosarcoma U2OS cells in vitro to doxorubicin treatment via inhibition of autophagy. In liver cancer cells (HepG2), miR-101 regulates the chemosensitivity of CDDP through inhibiting autophagy and inducing apoptosis (16). However, the regulatory mechanism of miR-101 and its function on chemoresistance in liver cancer remains unclear.

The aim of the present study was to examine the effects of miR-101 on the chemotherapeutic efficacy of CDDP in liver cancer cells. miR-101 mimic and miR-101 inhibitors were transfected into HepG2 cells to alter the expression levels of miR-101. Next, HepG2 cells were exposed to different concentrations of CDDP and cytotoxicity was assessed. Furthermore, the influence of miR-101 on expression and activity of the DNA-PKcs/protein kinase $\mathrm{B}(\mathrm{Akt})$ pathway were examined to explore the underlying mechanism. This study may provide new insight into the potential role of miR-101 as a novel therapeutic target for liver cancer treatment.

\section{Materials and methods}

Cell culture and treatments. Human liver cancer cells (HepG2) were obtained from American Type Culture Collection (ATCC) and maintained in Dulbecco's-modified Eagle's medium (DMEM; Invitrogen) supplemented with $10 \%$ fetal bovine serum (FBS; Invitrogen), $0.33 \%$ sodium bicarbonate and antibiotics $(100 \mathrm{U} / \mathrm{ml}$ penicillin and $0.1 \mathrm{mg} / \mathrm{ml}$ streptomycin) (Sigma-Aldrich) at $37^{\circ} \mathrm{C}$ in an atmosphere with $5 \% \mathrm{CO}_{2}$. For cisplatin (CDDP; Selleck Chemicals) treated, HepG2 cells were incubated with different concentrations of $\operatorname{CDDP}(0,2$ and $5 \mu \mathrm{M})$ for $24 \mathrm{~h}$.

Transfection of miRNA. The miR-101-mimic, control-mimic, inhibitor and inhibitor-control were designed and synthesized by Shanghai GenePharma Co., Ltd. miRNA ( 50 nM) was transfected using Lipofectamine ${ }^{\mathrm{TM}} 2000$ (Invitrogen) as recommended by the manufacturer. After $48 \mathrm{~h}$ of transfection, total RNA was extracted and the efficiency of transfection was verified by reverse transcription-quantitative PCR (RT-qPCR). For in vivo chemosensitivity assays, $\mathrm{miR}-101 \mathrm{mimic}$, control-mimic, miR-101 inhibitor and inhibitor-control sequences were embedded into the lentiviral pGIPZ plasmid (Genechem, Inc.). HepG2 cells were subsequently infected with the lentiviruses and inoculated into mice to produce tumor xenografts after $24 \mathrm{~h}$ of transfection. miRNA sequences were as follows: miR-101 mimic sense, 5'-UACAGUACUGUGAUAACUGAA-3' and antisense, 5'-CAGUUAUCACAGUACUGUAUU-3'; control-mimic sense, 5'-UUCUCCGAACGUGUCACGUTT-3' and antisense, 5'-ACGUGACACGUUCGGAGAATT-3'; miR-101 inhibitor, 5'-UUCAGUUAUCACAGUAUGUA-3'; and inhibitor-control, 5'-CAGUACUUUUGUGUAGUACAA-3'.

$R T$ - $q P C R$ analysis. Total RNA was prepared using TRIzol ${ }^{\circledR}$ reagent (Invitrogen). For miRNA quantification, cDNA was synthesized with specific miRNA reverse transcriptase primers using the TaqMan microRNA Reverse Transcription kit (Applied Biosystems). For mRNA quantification, cDNA was reversely transcribed at $37^{\circ} \mathrm{C}$ for $15 \mathrm{~min}$, and $95^{\circ} \mathrm{C}$ for 10 min using the Moloney murine leukemia virus (M-MLV) reverse transcriptase (Toyobo Life Science), according to the manufacturer's protocol. RNA and cDNA samples were stored at $-80^{\circ} \mathrm{C}$ until use. The qPCR analysis was performed on an Exicyler 96 sequence detection system (Bioneer Corporation). The final $50 \mu \mathrm{l}$ reaction mixture contained $25 \mu \mathrm{l}$ SYBR-Green PCR Master Mix (Toyobo), $2 \mu \mathrm{l}$ primer mix $(5 \mu \mathrm{M})$ and $10 \mathrm{ng}$ cDNA. Thermocycling was carried out as follows: $95^{\circ} \mathrm{C}$ for $2 \mathrm{~min}$ for denaturation; followed by 40 cycles of $94^{\circ} \mathrm{C}$ for $15 \mathrm{sec}, 55^{\circ} \mathrm{C}$ for $30 \mathrm{sec}$ for amplification; and $72^{\circ} \mathrm{C}$ for $30 \mathrm{sec}$ for termination. The standard curve was plotted using Origin 5.0 software (Originlab Corporation). The relative expression of miRNA was calculated using the $2^{-\Delta \Delta \mathrm{Cq}}$ method (17) and normalized to glyceraldehyde 3-phosphate dehydrogenase (GAPDH). The following primers for GAPDH were synthesized by Beijing Dingguo Changsheng Biotechnology Co., Ltd.: Sense, 5'-CCATGGAGAAGGCTGGGG-3' and antisense, 5'-CAAAGTTGTCATGGATGACC-3'.

Cell viability assay. Cell viability was measured using the Cell Counting Kit-8 (CCK-8) assay (Dojindo Molecular Technologies, Inc.) according to the manufacturer's protocol. HepG2 cells were cultured to 70-80\% confluence and treated with various concentrations of $\operatorname{CDDP}(0,2$ and $5 \mu \mathrm{M})$ for $24 \mathrm{~h}$. Absorbance at $450 \mathrm{~nm}$ was recorded using a Multiscan Mk3 plate reader (Thermo Fisher Scientific, Inc.). All measurements were performed at least in triplicate. CDDP was dissolved in dimethyl sulfoxide (DMSO; Sigma-Aldrich). Controls were treated with vehicle only at a final concentration of $0.1 \% \mathrm{w} / \mathrm{w}$.

Apoptosis analysis. Apoptosis was assessed in HepG2 cells using the Annexin V-fluorescein isothiocyanate (FITC)/propidium iodide(PI) assay $\left(\mathrm{Mbchem}^{\mathrm{TM}}\right.$, Shanghai, China) according to the manufacturer's instructions. For flow cytometry analysis, HepG2 cells were treated with CDDP and then collected and washed twice with cold PBS solution. Cells were suspended with $400 \mu \mathrm{l}$ binding buffer, incubated with $5 \mu \mathrm{l}$ Annexin V-FITC at $37^{\circ} \mathrm{C}$ for $15 \mathrm{~min}$ and $10 \mu \mathrm{PI}$ at $37^{\circ} \mathrm{C}$ for $5 \mathrm{~min}$ in the dark. Stained cells were immediately analyzed using a flow cytometer (Becton-Dickinson and Company) with Cell Quest 4.0.2 software (Becton-Dickinson and Company).

Comet assay. DNA single-strand breaks (SSBs) were evaluated with alkaline single-cell gel electrophoresis (comet assay) as described in previous studies $(18,19)$. After CDDP treatment, HepG2 cells were immersed in cell lysis solution $(2.5 \mathrm{M} \mathrm{NaCl}$, $100 \mathrm{mM} \mathrm{Na}{ }_{2}$ EDTA, $10 \mathrm{mM}$ Tris, $\mathrm{pH}$ 10.0; 1\% Triton X-100 and $10 \% \mathrm{DMSO}$ ) at $4^{\circ} \mathrm{C}$ for $1 \mathrm{~h}$, then placed in electrophoresis solution (300 $\mathrm{mM} \mathrm{NaOH}, 1 \mathrm{mM} \mathrm{Na} \mathrm{EDTA}_{2} \mathrm{pH}>13$ ) for $40 \mathrm{~min}$ at $4^{\circ} \mathrm{C}$. After electrophoresis $(25 \mathrm{~V}, \sim 300 \mathrm{~mA})$ and subsequent neutralization with Tris- $\mathrm{HCl}$ (400 mM, pH 7.5), cells were stained with PI ( $5 \mathrm{mg} / \mathrm{l}$; Sigma-Aldrich). Finally, the comet images were analyzed under a fluorescence microscope at $\mathrm{x} 40$ magnification with CASP comet analysis 1.2.2 software (Comet Assay Software Project Lab). The Olive tail moment of DNA (referred as DNA percentage in the tail) was used to evaluate the level of DNA damage. 
Measurement of reactive oxygen species (ROS). Levels of intracellular ROS were detected using the fluorescent probe 2',7'-dichlorofluorescein diacetate (DCFH-DA) (Sigma-Aldrich) according to the manufacturer's instructions. After treatment with CDDP as aforementioned, HepG2 cells were harvested, and cell solutions were incubated with $10 \mu \mathrm{M} \mathrm{DCFH}-\mathrm{DA}$ at $37^{\circ} \mathrm{C}$ for $20 \mathrm{~min}$. Serum-free culture medium and $50 \mu \mathrm{M}$ tert-butyl hydroperoxide (Sigma-Aldrich) were used as negative and positive controls, respectively. Fluorescence intensity was observed under a fluorescence microscope (Olympus BX-51) and analyzed using Image-pro plus 6.0 software (Media Cybernetics, Inc.). All experiments were performed at least three times with six replicates for each sample.

Tumor xenograft mouse model. For in vivo chemosensitivity assays, 4-week-old male BALB/c nude mice (weight 10-12 g) from Shanghai SLAC Laboratory Animal CO. Ltd. were housed and maintained in specific pathogen-free laminar flow cabinets. Treatments of animals were in accordance with the guidelines established by the Institutional Animal Care and Ethics Committee. BALB/c nude mice were randomly separated into five groups (20 mice in each group): Control group, mimic control, miR-101 mimic, inhibitor control, and miR-101 inhibitor group. Control HepG2 cells $\left(\sim 1 \times 10^{7}\right.$ cells $)$ and cells infected with lentivirus containing miR-101 mimic, mimic control, miR-101 inhibitor, or inhibitor control were subcutaneously inoculated into the right flank of nude mice. Ten days after injection of HepG2 cells, with no obvious enlargement of tumor volume, each group of mice was further divided into two subgroups, CDDP (-) and CDDP (+). Mice in the CDDP (+) group received intraperitoneal injection of CDDP at a dose of $5 \mathrm{mg} / \mathrm{kg}$ every 5 days for 20 days. Tumor diameter and tumor volume were examined every five days, and tumor volume (V) was calculated using the equation $\mathrm{V}=\mathrm{AxB}^{2} / 2\left(\mathrm{~mm}^{3}\right)$ where $\mathrm{A}$ is the largest diameter and $\mathrm{B}$ is the perpendicular diameter. At different time points, four tumor-bearing mice were sacrificed, and xenograft tumors were separated and weighed. The average tumor weights of each group were calculated. During the experimental procedure, animals were maintained in a specific pathogen-free environment in a laminar flow hood.

Luciferase assay. The putative miRNA binding sites from the 3'-UTR of DNA-PKcs or a mutant version of this 3'-UTR were amplified by PCR using DNA samples from HepG2 cells with a TaqMan ${ }^{\circledR}$ Universal PCR Master Mix (Applied Biosystems; Thermo Fisher Scientific, Inc.) and inserted into pGL3-control luciferase reporter vectors (Promega) according to Yan et al (13). The sequences of primers were listed as follows: Wild-type DNA-PKcs (sense, 5'-CTAGCTTTG CATTGAATTTGGGATAACTTCAA-3', antisense, 5'-AGC TTTGAAGTTATCCCAAATTCAATGCAAAG-3'); mutant DNA-PKcs (sense, 5'-CTAGACATAAAAGTGCTTCAA AAATCCCATGG-3', antisense, 5'-AGCTCCATGGGATTT TTGAAGCACTTTTATGT-3'). The thermocycling conditions of PCR were as follows: $95^{\circ} \mathrm{C}$ for $2 \mathrm{~min}$; then 42 cycles of $95^{\circ} \mathrm{C}$ for $5 \mathrm{sec}, 63^{\circ} \mathrm{C}$ for $20 \mathrm{sec}$ and $72^{\circ} \mathrm{C}$ for $10 \mathrm{sec}$. Constructed vectors were sequenced and denoted as pGL3-DNA-PKcs-WT and pGL3-DNA-PKcs-MUT, respectively. HepG2 cells were cotransfected with $0.05 \mathrm{mg}$ constructed luciferase reporters, $0.01 \mathrm{mg}$ control pRL-TK vector containing Renilla luciferase and $100 \mathrm{nM}$ miR-101 or miRNA-control using Lipofectamine 2000 (Invitrogen). Cells were harvested $48 \mathrm{~h}$ after transfection and measured with a Dual Luciferase Assay kit (Promega) using the luminescence microplate reader LUMIstar Galaxy (BMG Labtech $\mathrm{GmbH}$ ) according to the manufacturer's protocol. Firefly luciferase activity was normalized to Renilla luciferase activity for each transfected well.

Western blotting. Total protein samples and nuclear protein samples were prepared after CDDP treatments using Mammalian Protein Extraction Reagent and the Nuclear and Cytoplasmic Extraction Reagent Kit (Thermo Fisher Scientific, Inc.), respectively. Protein concentration was determined using the bicinchoninic acid protein assay (Thermo Fisher Scientific, Inc.). Protein samples (60 $\mu \mathrm{g}$ per sample) were separated by $8 \%$ SDS-PAGE and transferred onto nitrocellulose membranes (Merck KGaA). Membranes were then blocked with $5 \%$ skim milk at $37^{\circ} \mathrm{C}$ for $1 \mathrm{~h}$, followed by successive incubation with primary antibodies for $12 \mathrm{~h}$ at $4^{\circ} \mathrm{C}$ and corresponding secondary antibodies for $4 \mathrm{~h}$ at $4^{\circ} \mathrm{C}$. The primary antibodies were as follow: NF- $\mathrm{B}(\mathrm{p} 65 ; 1: 1,000$; cat. no. 8242), phospho-IKK $\alpha / \beta$ (1:1,000; cat. no. 2697$),$ IKK $\alpha / \beta$ (1:1,000; cat. no. 2682/2684), p-IкB $\alpha$ (1:1,000; cat. no. 2859), I $\mathrm{B} \alpha(1: 1,000$; cat. no. 4812), p-Akt (Ser473; 1:1,000; cat. no. 9271), H3 (1:1,000; cat. no. 4499), Akt (1:1,000; cat. no. 9272), p53 (1:1,000; cat. no. 9282), caspase-3 (1:1,000; cat. no. 9662) and mammalian target of rapamycin (mTOR; 1:1,000; cat. no. 2972) antibodies were all purchased from Cell Signaling Technology, Inc. The DNA-PKcs antibody (1:1,000; cat. no. sc-135886) was purchased from Santa Cruz Biotechnology, Inc. GAPDH (1:1,000; cat. no. 5465-040) antibody was purchased from Multisciences (Lianke) Biotech Co., Ltd. Anti-Rabbit IgG (H+L)/HRP and anti-Mouse IgG $(\mathrm{H}+\mathrm{L}) / \mathrm{HRP}$ secondary antibodies were purchased from Beijing Dingguo Changsheng Biotechnology Co., Ltd. Finally, blots were visualized using enhanced chemiluminescence (cat. no. P0018; Beyotime Institute of Biotechnology) and quantified using the ChemiImager system (Alpha Innotech). GAPDH was used as the internal reference, and $\mathrm{H} 3$ was used as the nuclear protein loading control. Prior to quantifying the ratio of phosphorylated to total protein, the intensities of phosphorylated and total protein bands were normalized to GAPDH or H3. Each experiment was repeated at least three times with three replicates for each sample.

Caspase activity assay. Caspase 3 activity was measured with the Caspase 3 Assay Kit (Abcam) according to the manufacturer's protocol. Following treatment, HepG2 cells were collected and resuspended in cell lysis buffer. The supernatant (cytosolic extract) was collected and incubated with reactive buffer at $37^{\circ} \mathrm{C}$ for $1-2 \mathrm{~h}$, and the absorbance was recorded at $405 \mathrm{~nm}$ using a Multiscan Mk3 plate reader (Thermo Fisher Scientific, Inc.).

Statistical analyses. All experiments were performed in triplicate with at least three replicates for each sample. Data are expressed as the mean \pm standard error of the mean (SEM). Two-way analysis of variance (ANOVA) was performed to test the comparisons and corrected by Tukey's post hoc test. $\mathrm{P}<0.05$ was considered to indicate a statistically significant difference. 


\section{Results}

miR-101 affects cell survival and apoptosis in HepG2 cells exposed to CDDP. To investigate the effects of miR-101 on the therapeutic efficiency of CDDP treatment in HepG2 cells, miR-101 expression was altered through transfection with a miR-101 mimic or miR-101 inhibitor. Expression levels of miR-101 were confirmed by RT-qPCR. miR-101 mimic-treated cells exhibited 15.8-fold higher miR-101 expression levels compared with that of mimic-control cells and wild-type HepG2 cells. In contrast, miR-101 inhibitor-treated cells exhibited 70\% reduced expression compared with control-treated cells (Fig. 1A). These HepG2 cells with differing expression of miR-101 were treated with CDDP $(0,2$ or $5 \mu \mathrm{M})$ in subsequent experiments.

Cell viability was assessed using the CCK- 8 assay. Transfection with mimic-control and inhibitor-control had no effect on cell viability compared with wild-type HepG2 cells (Fig. 1B). Cell survival reduced by $\sim 16.8 \pm 3.9$ and $30.2 \pm 5.5 \%$ after 24-h treatment with 2 and $5 \mu \mathrm{M}$ CDDP, respectively in wild-type HepG2 cells. miR-101 overexpression significantly enhanced the sensitivity of HepG2 cells to CDDP treatment compared to the mimic control group, with cell viability reduced by $25.6 \pm 5.1$ and $47.4 \pm 4.0 \%$ for the two doses of CDDP. In addition, miR-101 knockdown partially attenuated the cytotoxic effects of CDDP treatment, with viability decreased by only $\sim 10.5$ and $17.3 \%$ for these two doses.

To investigate the role of miR-101 in apoptosis of HepG2 cells, CDDP-induced apoptosis was assessed by flow cytometry. The wild-type HepG2 cells had an apoptosis rate of $13.5 \pm 1.2$ and $24.7 \pm 1.3 \%$ in response to 2 and $5 \mu \mathrm{M}$ of CDDP treatment. The miR-101-overexpressing cells exhibited an increased apoptosis rate compared with the mimic control group $(19.4 \pm 2.05$ and $33.9 \pm 2.76 \%$; $\mathrm{P}<0.05)$, whereas miR-101-knockdown groups exhibited a reduced apoptosis rate compared with the inhibitor control in response to CDDP treatment $(6.3 \pm 0.74$ and $9.8 \pm 1.27 \%$; $\mathrm{P}<0.05)$ (Fig. $1 \mathrm{C}$ and $\mathrm{D}$ ). These findings indicate that increased miR-101 expression may enhance cisplatin sensitivity in HepG2 cells.

miR-101 expression impacts DNA damage and ROS levels in HepG2 cells exposed to CDDP. Increased repair or tolerance of DNA damage is one of the potential mechanisms for cisplatin resistance $(20,21)$. In the present study, the results of a comet assay (Fig. 2A and B) showed that CDDP induced significant DNA SSB damage in wild-type HepG2 cells, with the DNA damage rate increasing from $\sim 5.6 \pm 1.0 \%$ in untreated cells to $14.8 \pm 2.9$ and $23.7 \pm 3.1 \%$ after treatment for $24 \mathrm{~h}$ with 2 and $5 \mu \mathrm{M}$ of CDDP, respectively. miR-101 overexpression significantly enhanced DNA damage, with the DNA damage rate increasing to $23.6 \pm 3.2$ and $35.9 \pm 4.9 \%(\mathrm{P}<0.05$; vs. mimic control group) for the two doses of CDDP. miR-101 inhibition decreased CDDP-induced DNA damage to 10.1 \pm 3.2 and $17.3 \pm 3.0 \%$ ( $\mathrm{P}<0.05$; vs. inhibitor control).

In response to treatment with 2 and $5 \mu \mathrm{M} \mathrm{CDDP}$ for $24 \mathrm{~h}$, intracellular ROS significantly increased to $\sim 235$ and $305 \%$ of untreated cells in wild-type HepG2 cells (Fig. 2C). A similar degree of ROS increase also occurred in HepG2 cells transfected with control-mimic and inhibitor-control. With miR-101 overexpression, ROS levels of the groups treated with 2 and $5 \mu \mathrm{M} \mathrm{CDDP}$ increased to $289 \pm 15.8$ and $356 \pm 12.2 \%$ compared with the untreated group, respectively. In cells with knockdown of miR-101, ROS levels increased to $205 \pm 17.2$ and $280 \pm 32.5 \%$ of the untreated group (Fig. $2 \mathrm{C}$ and D). These results suggest that the chemosensitizing effect of miR-101 in HepG2 cells may be associated with oxidative stress.

miR-101 expression regulates tumor growth and sensitivity to $C D D P$ in BALB/c nude mice. To assess tumor growth rates in vivo, HepG2 cells were infected with lentivirus containing miR-101 mimic, control-mimic, miR-101 inhibitor, or inhibitor control. Expression levels of miR-101 were confirmed by RT-qPCR. miR-101 mimic-transfected cells exhibited 8.7-fold higher expression compared with that of mimic-control-transfected cells and control HepG2 cells. By contrast, the expression level of miR-101 in cells transfected with miR-101 inhibitor reduced by $81 \%$ compared with that of control cells (Fig. 3A). Next, infected HepG2 cells were subcutaneously inoculated into nude mice (day 0). After 10 days, half the mice were treated with CDDP at $5 \mathrm{mg} / \mathrm{kg}$ every 5 days for 20 days, and tumor volume and weight were examined every 5 days. For non-CDDP groups, treatment of miR-101 mimic control or inhibitor control had no effects on tumor growth compared to controls. miR-101 overexpression, however, inhibited tumor growth in vivo, and miR-101 suppression promoted tumor growth (Fig. 3B, C and D). CDDP treatment suppressed tumor growth (Fig. 3D), with a mean average inhibition rate of $37.5 \%$ for tumor weight on day 25 . Combined treatment of CDDP plus miR-101 exerted the most marked inhibition of growth, reducing tumor weight by $55.6 \%$ on day 25. By contrast, addition of the miR-101 inhibitor attenuated the effects of CDDP to $25.8 \%$ inhibition. Tumor growth in the groups treated with miR-101 mimic control and CDDP and with miR-101 inhibitor control and CDDP was roughly equivalent to that of the control plus CDDP groups (Fig. 3C and D).

miR-101 expression regulates protein expression of the DNA-PKcs/Akt pathway and alters expression of apoptosis related proteins. A luciferase reporter assay was performed to identify whether DNA-PKcs is a target of miR-101. As shown in Fig. 4, transfection with miR-101 mimic significantly suppressed the luciferase activity in cells co-transfected with DNA-PKcs 3'-UTR-containing plasmid, while having no effect on cells containing plasmids carrying a mutant 3'UTR sequence. These results suggested that miR-101 efficiently targets DNA-PKcs via binding to the 3'-UTR of DNA-PKcs in HepG2 cells. To explore the underlying molecular mechanism of miR-101-mediated chemosensitivity, expression of DNA-PKcs/Akt/NF- $\mathrm{kB}$ pathway related proteins, including DNA-PKcs, Akt, phosphorylated Akt, mTOR, caspase-3, p53, phospho-IKK- $\alpha / \beta$ and NF- $\kappa \mathrm{B}$ were assessed. Western blot results revealed that miR-101 mimic decreased Akt phosphorylation in HepG2 cells compared to the control group, and no change was observed in total levels of Akt protein $(\mathrm{P}<0.05$; Fig. 5A and $\mathrm{C})$. In addition, phosphorylation level of the downstream target protein mTOR was significantly downregulated (Fig. 5A and C). miR-101 inhibitor increased expression of DNA-PKcs, p-Akt and p-mTOR compared with control group (Fig. 5A and C), indicating that miR-101 may downregulate the DNA-PKcs/Akt pathway. In addition, CDDP treatment $(2 \mu \mathrm{M})$ for $24 \mathrm{~h}$ reduced the expression of DNA-PKcs, p-Akt and p-mTOR compared with 

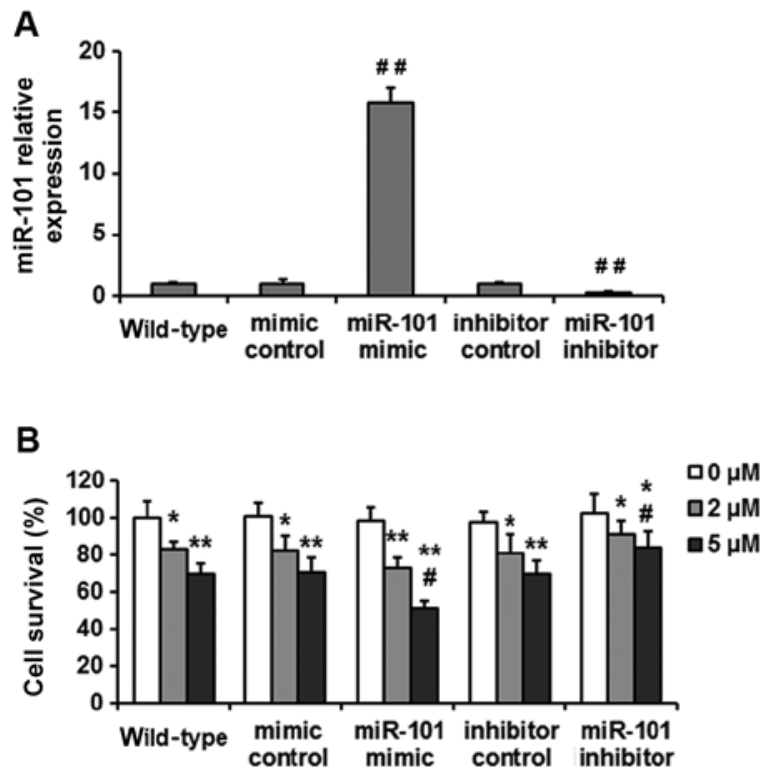
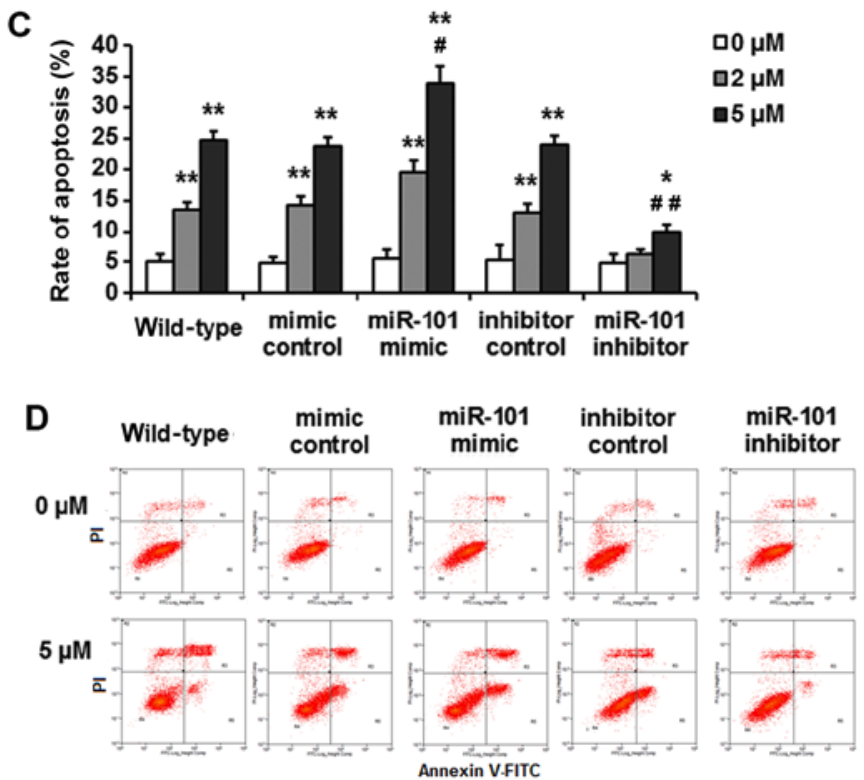

Figure 1. miR-101 impacts cell survival and apoptosis in HepG2 cells exposed to CDDP. HepG2 cells transfected with miR-101-mimic, mimic control, miR-101 inhibitor and inhibitor control were subsequently treated with CDDP $(0,2$ and $5 \mu \mathrm{M})$. (A) miR-101 expression; (B) cell viability; (C) apoptosis rate assessed by Annexin V-FITC/PI staining; (D) representative images of apoptosis ( 0 and $5 \mu \mathrm{M}$ CDDP groups). Data are mean \pm SEM of three separate experiments with three replicates for each sample. ${ }^{*} \mathrm{P}<0.05$ and ${ }^{* *} \mathrm{P}<0.01$ compared to $0 \mu \mathrm{M}$ group; ${ }^{\#} \mathrm{P}<0.05$ and ${ }^{\# \#} \mathrm{P}<0.01$ compared to mimic control/inhibitor control groups. miR-101, microRNA-101; CDDP, cisplatin; FITC, fluorescein isothiocyanate; PI, propidium iodide.

A

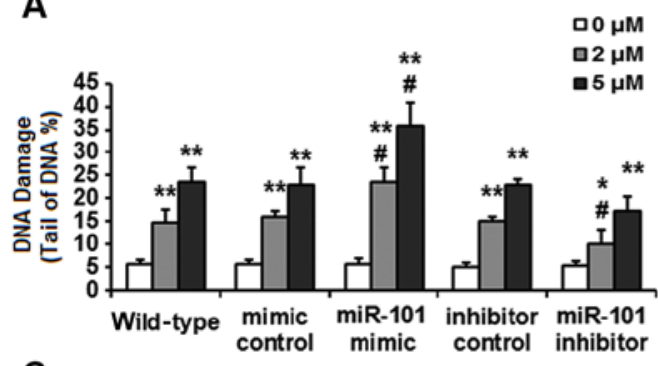

$c$

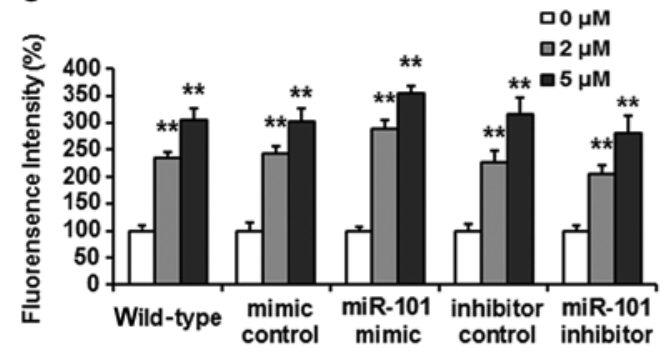

B

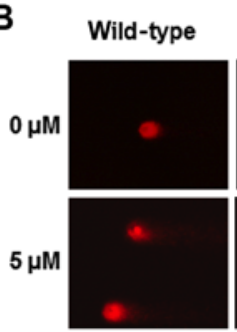

D

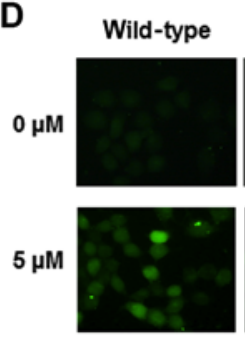

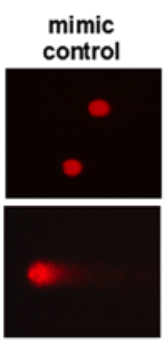
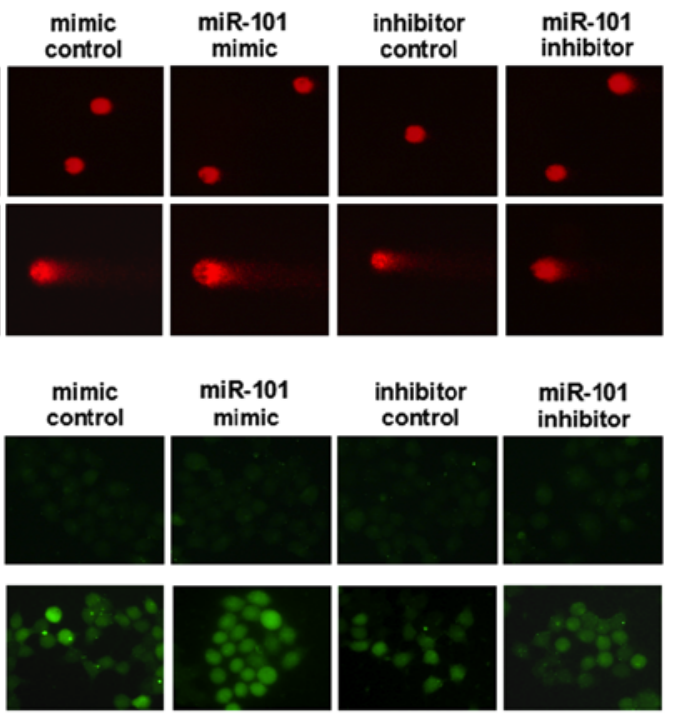

inhibitor

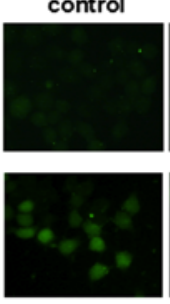

miR-101 inhibitor

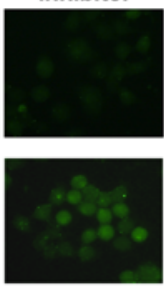

Figure 2. miR-101 affects DNA damage and ROS levels in HepG2 cells exposed to CDDP. HepG2 cells transfected with miR-101-mimic, mimic control, miR-101 inhibitor and inhibitor control were subsequently treated with CDDP $(0,2$ and $5 \mu \mathrm{M})$. (A) DNA single-strand breaks evaluated by comet assay; (B) representative images of comet assay (0 and $5 \mu \mathrm{M}$ CDDP groups); (C) level of intracellular ROS assessed by the fluorescent probe DCFH-DA; (D) representative fluorescent images of ROS levels ( 0 and $5 \mu \mathrm{M}$ CDDP groups). ${ }^{*} \mathrm{P}<0.05$ and ${ }^{* *} \mathrm{P}<0.01$ compared to $0 \mu \mathrm{M}$ group; ${ }^{\#} \mathrm{P}<0.05$ compared to wide-type groups. miR-101, microRNA-101; CDDP, cisplatin; ROS, reactive oxygen species; DCFH-DA, dichloro-dihydro-fluorescein diacetate.

the CDDP treatment alone, while the pro-apoptotic factors p53 and caspase-3 were elevated in response to CDDP treatment (Fig. 5A-C). Caspase 3 activity was also significantly increased in cells treated with CDDP and miR-101 mimic compared to that in the control or control + CDDP groups (Fig. 5D), consistent with the effect of miR-101 mimic and CDDP on apoptosis in vitro (Fig. 1C).

The $N F-\kappa B$ pathway serves crucial roles in anticancer strategies. Consistent with the results for the DNA-PKcs/Akt pathway, miR-101 mimic also inhibited the NF- $\mathrm{B}$ pathway, as evidenced by the downregulation of nuclear $N F-\kappa B$ $(\mathrm{Nu}-\mathrm{NF}-\kappa \mathrm{B}, \mathrm{p} 65)$ and decreased phosphorylation of IKK $\alpha / \beta$ and $\mathrm{I} \kappa \mathrm{B} \alpha$. Additionally, miR-101 inhibitor activated the $\mathrm{NF}-\kappa \mathrm{B}$ pathway, resulting in enhanced protein expression and phosphorylation (Fig. 5B and C). This study also showed that expression of Nu-NF- $\kappa \mathrm{B}$ and phosphorylation of IKK $\alpha / \beta$ and I $\mathrm{B} \alpha$ were reduced in HepG2 cells treated with CDDP alone for $24 \mathrm{~h}$ (Fig. 5B and C). 
A

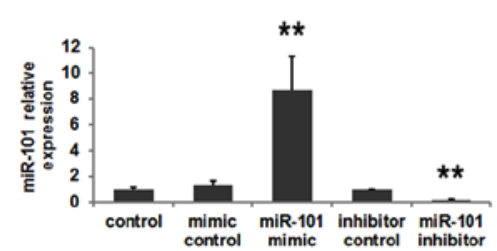

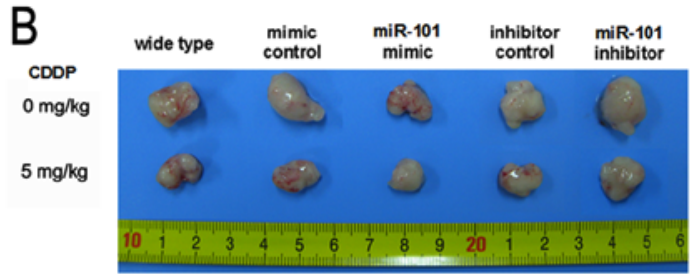

D
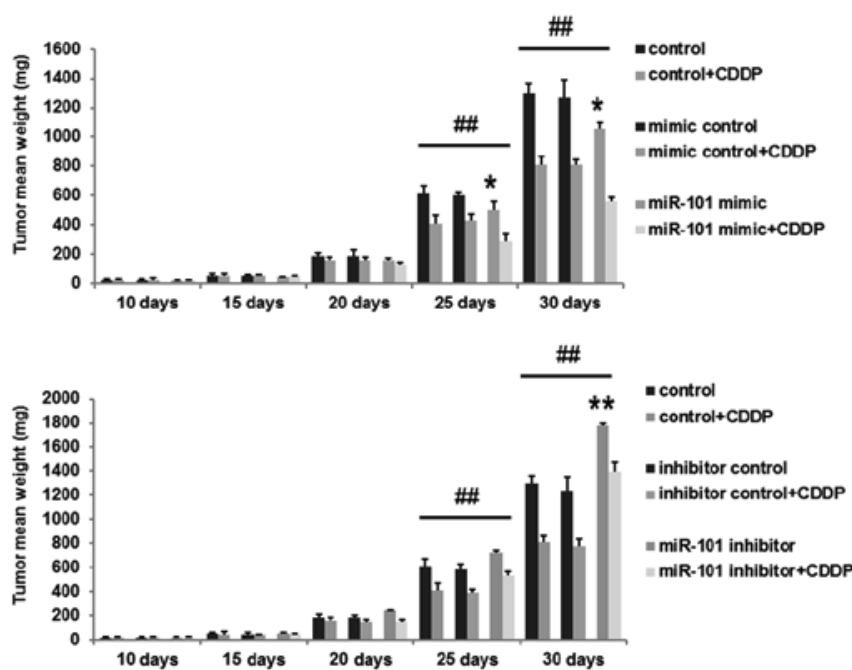

Figure 3. miR-101 influences the inhibition of tumor growth by CDDP in BALB/c nude mice. HepG2 cells infected with lentiviruses carrying miR-101-mimic, mimic control, miR-101-inhibitor and inhibitor control were subcutaneously inoculated into nude mice. CDDP (5 mg/kg) was administered every 5 days for 20 days. (A) miR-101 expression in HepG2 cells following lentiviral-mediated transfection was determined using RT-qPCR. (B) Representative images of tumors. (C) Mean volume and (D) weight of tumors, miR-101 mimic and controls in upper graphs and miR-101 inhibitor and controls in lower graphs. ${ }^{*}<0.05$, ${ }^{* *} \mathrm{P}<0.01$ vs. mimic control/inhibitor control groups. ${ }^{\# \#} \mathrm{P}<0.01$ vs. non-CDDP groups. miR-101, microRNA-101; CDDP, cisplatin.

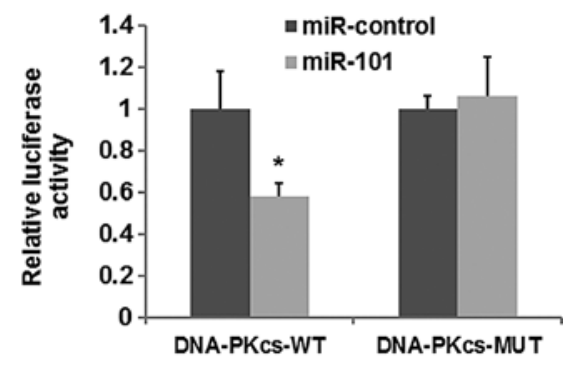

Figure 4. DNA-PKcs is a direct target of miR-101 in HepG2 cells. Relative luciferase activity of HepG2 cells co-transfected with plasmids containing DNA-PKcs-WT 3'-UTR or DNA-PKcs-MUT 3'-UTR and miR-101 or miR-control. Data are mean \pm SEM of three separate experiments with three replicates for each sample. " $\mathrm{P}<0.05$ compared to miR-control group. miR-101, microRNA-101; DNA-PKcs, DNA-dependent protein kinase catalytic subunit; 3'-UTR, 3'-untranslated region; WT, wild type; MUT, mutant.

\section{Discussion}

CDDP is an effective cytotoxic platinum agent used in chemotherapy, particularly in patients with unresectable liver cancer(22). However, chemoresistance to CDDP has become a barrier to its clinical effectiveness, with low response rates varying from $22-29 \%$ in liver cancer treatment (23). Although several factors contributing to CDDP resistance have been reported $(24,25)$, the underlying mechanism of acquired chemoresistance remains poorly understood. Drug resistance is an important issue that remains to be resolved in liver cancer chemotherapy.
Numerous studies have reported that miRNAs regulate the response to carcinogenesis and chemosensitivity in multiple types of cancer, including liver cancer $(26,27)$. miR-142-3p targets autophagy protein 5 and autophagy-related protein 16-1 to inactivate autophagy and sensitizes liver cancer to sorafenib (28). miR-205-5p regulates the chemotherapeutic resistance of liver cancer to 5-fluorouracil by targeting the PTEN/JNK/ANXA3 pathway (29). miR-101 was initially identified as a tumor suppressor miRNA in a human cancer by $\mathrm{Xu}$ et al (16). It was demonstrated that miR-101 serves an important role in cisplatin-induced apoptosis in liver cancer cells through inhibition of autophagy via modulating the expression of Ras-related protein RAB5A, stathmin and cysteine protease ATG4D. He et al (30) reported that miR-101 sensitizes liver cancer cell lines to doxorubicin-induced apoptosis by targeting apoptosis regulator MCL1. In vitro testing demonstrated that miR-101 binds to the 3'-UTR of DNA-PKcs to regulate protein levels of DNA-PKcs and mediates the sensitivity of lung cancer cells to radiation (13). However, the molecular mechanism of how miR-101 regulates resistance of liver cancer cells to CDDP treatment remains unclear.

CDDP induces DNA-adducts and DNA damage by DNA crosslinking via displacement of the chloride ligand, which could consequently induce cell proliferation inhibition and cell death (24). As shown in Fig. 2, miR-101 overexpression enhanced CDDP-induced DNA damage, and miR-101 knockdown partially relieved DNA single-strand damage. This may partially explain the findings in this study that overexpression 
A

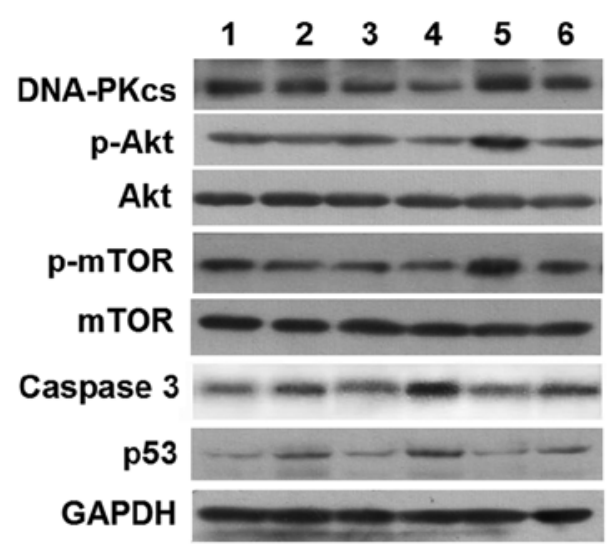

C
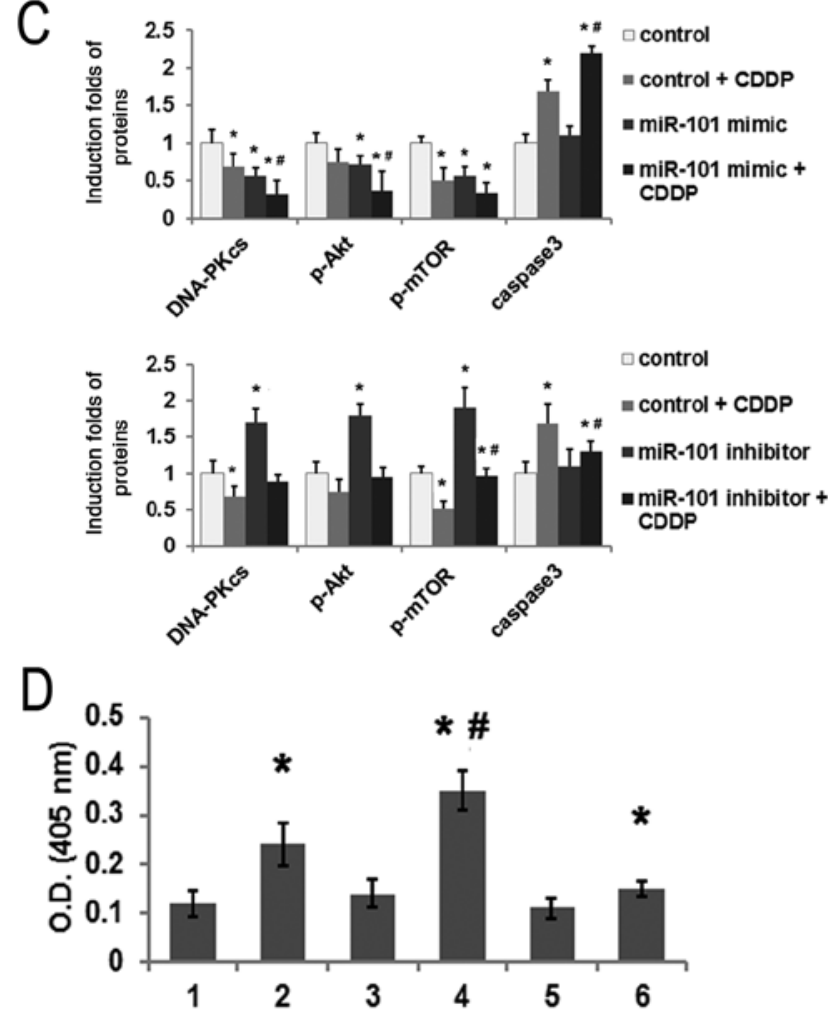

B

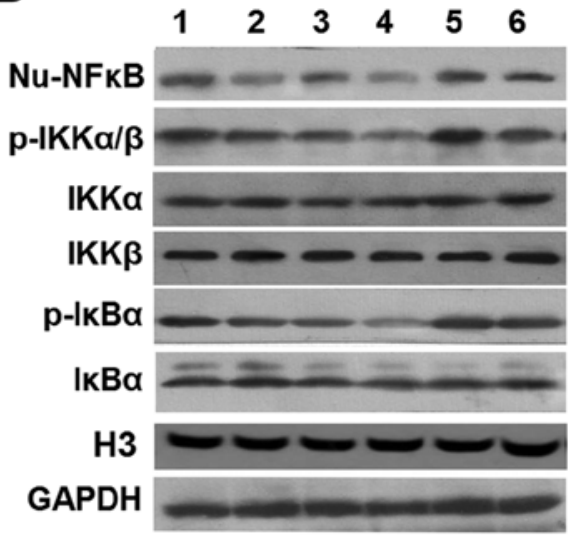

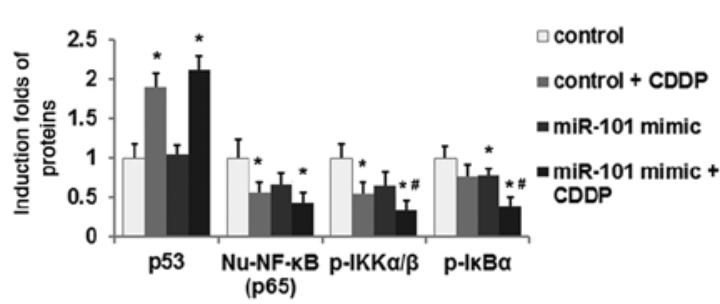

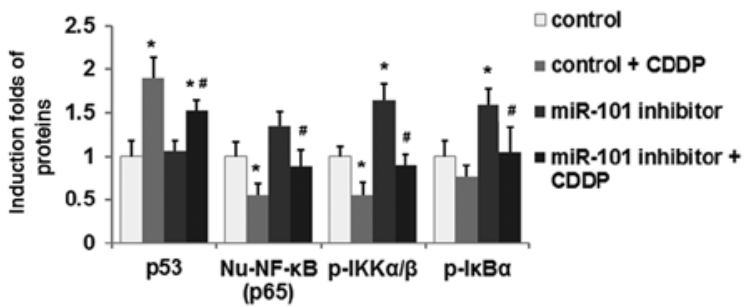

Figure 5. miR-101 affects protein expression of the DNA-PKcs/Akt/NF- $\kappa$ B pathway. HepG2 cells were transfected with miR-101 mimic or miR-101 inhibitor and treated with 0 or $5 \mu \mathrm{M}$ CDDP. (A) Representative images of western blot analysis of DNA-PKcs, p-Akt, Akt, p-mTOR, mTOR, caspase-3, p53 and GAPDH;

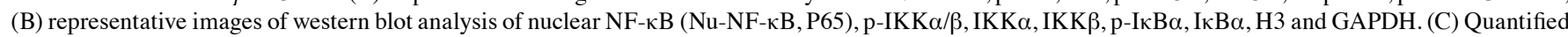
results of western blot analysis with three replicates for each sample. Intensity of bands for DNA-PKcs, caspase-3 and p53 were normalized using GAPDH as the internal reference. Bands for p-Akt, p-mTOR, p-IKK $\alpha / \beta$ and p-I $\kappa$ B $\alpha$ were normalized to GAPDH/H3 and are presented as a ratio of phosphorylated to total protein for each. Expression of NF- $\kappa \mathrm{B}$ was quantified using $\mathrm{H} 3$ as the internal reference. (D) Activity of caspase 3 . 1, control; 2 , control + CDDP; 3 , miR-101 mimic; 4, miR-101 mimic + CDDP; 5, miR-101 inhibitor; and 6, miR-101 inhibitor + CDDP. ${ }^{*}<<0.05$ compared to control group. ${ }^{\#} \mathrm{P}<0.05$ compared to control + CDDP group. miR-101, microRNA-101; DNA-PKcs, DNA-dependent protein kinase catalytic subunit; CDDP, cisplatin; Akt, protein kinase B; p-Akt, phosphorylated Akt; mTOR, mammalian target of rapamycin; p-mTOR, phosphorylated mTOR; p53, tumor protein P53; GAPDH, glyceraldehyde-3-phosphate dehydrogenase; NF- $\kappa$ B, nuclear factor $\kappa \mathrm{B}$; IKK $\alpha / \beta$, inhibitor of $\kappa \mathrm{B}$ kinase $\alpha / \beta$; p-IKK $\alpha / \beta$, phosphorylated IKK $\alpha / \beta$; I $\kappa \mathrm{B} \alpha$, inhibitor of NF- $\kappa \mathrm{B} \alpha$; $\mathrm{p}$-I $\kappa \mathrm{B} \alpha$, phosphorylated I $\mathrm{B} \alpha ; \mathrm{H} 3$, histone 3 .

of miR-101 significantly sensitized HepG2 cells to CDDP treatment, while downregulation of miR-101 reduced chemosensitivity (Fig. 1). Overexpression of miR-101 significantly elevated ROS production, while miR-101 downregulation reduced ROS levels induced by CDDP treatment in HepG2 cells, indicating that CDDP cytotoxicity was associated with intracellular redox status. A xenograft mouse model further confirmed that miR-101 overexpression inhibited tumor growth, and miR-101 knockdown could promote tumor growth (Fig. 3). These results suggest that miR-101 may increase cisplatin sensitivity in HepG2 cells through modulation of DNA damage and intracellular ROS levels.

The PI3K/Akt pathway is involved in stimulation of tumor cell survival, invasive behavior and chemosensitivity in numerous types of malignancy $(31,32)$. As one of the PI3K family members, DNA-PK plays an important role in NHEJ 
to repair DSBs, which are a major mechanism of CDDP cytotoxicity (23). A previous study demonstrated that suppression of DNA-PKcs results in sensitization of HepG2 cells to CDDP treatment (33). In the present study, the western blot results revealed that miR-101 overexpression markedly reduced the expression of DNA-PKcs, as well as phosphorylation of Akt and mTOR. By contrast, miR-101 knockdown increased the expression of DNA-PKcs and further elevated the activity of $\mathrm{Akt} / \mathrm{mTOR}$ signaling. These results confirm a regulatory role for DNA-PKcs in chemoresistance mediated by miR-101. Moreover, combining treatment of miR-101 mimic and CDDP significantly increased the expression of the apoptotic protein caspase 3 compared with CDDP treatment alone, and miR-101 knockdown partially reversed caspase- 3 expression induced by CDDP treatment, consistent with results of the apoptosis assay.

Two serine threonine IкB kinases, IKK $\alpha$ and IKK $\beta$, are responsible for phosphorylation, ubiquitination and subsequent degradation of I $\kappa \mathrm{B}$ molecules, which facilitate the release of NF- $\kappa B$ from its binding with I $\mathrm{BB}$ (34). This allows free NF- $\kappa \mathrm{B}$ to translocate from the cytoplasmic into the nucleus, where it exerts transcriptional activity (35). Physiological processes such as cell proliferation, invasion and cell death are regulated by NF- $\kappa B$ release (36). CDDP is a potent inhibitor of NF- $\kappa B$ pathway activation that inhibits tumor growth (37). Western blot results in the present study revealed that that CDDP treatment led to reduced nuclear translocation of NF- $\mathrm{KB} / \mathrm{p} 65$ protein, as well as reduced phosphorylation levels of IKK $\alpha / \beta$ and I $\mathrm{I} B$. Moreover, suppression of NF- $\mathrm{KB}$ by CDDP was further aggravated by miR-101 mimic, which may make HepG2 cells more susceptible to chemotherapeutic agents. These data suggest that miR-101 attenuates chemoresistance to CDDP in HepG2 cells through the DNA-PKcs/Akt/NF-kB pathway.

In conclusion, miR-101 overexpression augmented the cytotoxicity of CDDP and reduced chemoresistance in HepG2 cells, and these phenomena were associated with negative regulation of the DNA-PKcs/Akt/NF- $\mathrm{BB}$ signaling pathway. The present study provides new insight into a potential alternative therapeutic strategy for liver cancer treatment using miR-101 as antitumor miRNA.

\section{Acknowledgements}

Not applicable.

\section{Funding}

This study was supported by the National Natural Science Funds of China (grant nos. 81272393 and 81702335).

\section{Availability of data and materials}

All data generated or analyzed during this study are included in this published article.

\section{Authors' contributions}

ZC, XY, FL and JC conducted the experiments. SC designed the research. JS, JXS and CL acquired and analyzed the data. $\mathrm{ZC}$ and $\mathrm{SC}$ drafted and revised the manuscript.

\section{Ethics approval and consent to participate}

Animal experiments were approved by the Experimental Animal Ethics Committee of Second Military Medical University.

\section{Patient consent for publication}

Not applicable.

\section{Competing interests}

The authors declare that they have no competing interests.

\section{References}

1. Argyrou C, Moris D and Vernadakis S: Hepatocellular carcinoma development in non-alcoholic fatty liver disease and non-alcoholic steatohepatitis. Is it going to be the 'Plague' of the 21 st century? A literature review focusing on pathogenesis, prevention and treatment. J BUON 22: 6-20, 2017.

2. Llovet JM, Burroughs A and Bruix J: Hepatocellular carcinoma. Lancet 362: 1907-1917, 2003.

3. Lin DY, Lin SM and Liaw YF: Non-surgical treatment of hepatocellular carcinoma. J Gastroenterol Hepatol 12: S319-S328, 1997.

4. Ueno H, Okada S, Okusaka T, Ikeda M and Kuriyama H: Phase I and pharmacokinetic study of 5-fluorouracil administered by 5-day continuous infusion in patients with hepatocellular carcinoma. Cancer Chemother Pharmacol 49: 155-160, 2002.

5. Falkson G, Ryan LM, Johnson LA, Simson IW, Coetzer BJ, Carbone PP, Creech RH and Schutt AJ: A random phase II study of mitoxantrone and cisplatin in patients with hepatocellular carcinoma. An ECOG study. Cancer 60: 2141-2145, 1987.

6. Ghosh S: Cisplatin: The first metal based anticancer drug. Bioorg Chem 88: 102925, 2019.

7. Roos WP, Frohnapfel L, Quiros S, Ringel F and Kaina B: XRCC3 contributes to temozolomide resistance of glioblastoma cells by promoting DNA double-strand break repair. Cancer Lett 424: 119-126, 2018.

8. Sirbu BM and Cortez D: DNA damage response: Three levels of DNA repair regulation. Cold Spring Harb Perspect Biol 5: a012724, 2013.

9. Panta GR, Kaur S, Cavin LG, Cortés ML, Mercurio F, Lothstein L, Sweatman TW, Israel M and Arsura M: ATM and the catalytic subunit of DNA-dependent protein kinase activate NF-kappaB through a common MEK/extracellular signal-regulated kinase/p90(rsk) signaling pathway in response to distinct forms of DNA damage. Mol Cell Biol 24: 1823-1835, 2004.

10. Elliott SL, Crawford C, Mulligan E, Summerfield G, Newton P, Wallis J, Mainou-Fowler T, Evans P, Bedwell C, Durkacz BW and Willmore E: Mitoxantrone in combination with an inhibitor of DNA-dependent protein kinase: A potential therapy for high risk B-cell chronic lymphocytic leukaemia. Br J Haematol 152: 61-71, 2011.

11. Kim SH,Um JH, Dong-Won B, Kwon BH, Kim DW, Chung BS and Kang CD: Potentiation of chemosensitivity in multidrug-resistant human leukemia CEM cells by inhibition of DNA-dependent protein kinase using wortmannin. Leuk Res 24: 917-925, 2000.

12. Bartel DP: MicroRNAs: Genomics, biogenesis, mechanism, and function. Cell 116: 281-297, 2004.

13. Yan D, Ng WL, Zhang X, Wang P, Zhang Z, Mo YY, Mao H, Hao C, Olson JJ, Curran WJ and Wang Y: Targeting DNA-PKcs and ATM with miR-101 sensitizes tumors to radiation. PLoS One 5: e11397, 2010

14. Hu H, He Y, Wang Y, Chen W, Hu B and Gu Y: micorRNA-101 silences DNA-PKcs and sensitizes pancreatic cancer cells to gemcitabine. Biochem Biophys Res Commun 483: 725-731, 2017.

15. Chang Z, Huo L, Li K, Wu Y and Hu Z: Blocked autophagy by miR-101 enhances osteosarcoma cell chemosensitivity in vitro. ScientificWorldJournal 2014: 794756, 2014.

16. Xu Y, An Y, Wang Y, Zhang C, Zhang H, Huang C, Jiang H, Wang $X$ and Li X: miR-101 inhibits autophagy and enhances cisplatin-induced apoptosis in hepatocellular carcinoma cells. Oncol Rep 29: 2019-2024, 2013. 
17. Livak KJ and Schmittgen TD: Analysis of relative gene expression data using real-time quantitative PCR and the 2(-Delta Delta C(T)) method. Methods 25: 402-408, 2001.

18. Tice RR, Agurell E, Anderson D, Burlinson B, Hartmann A, Kobayashi H, Miyamae Y, Rojas E, Ryu JC and Sasaki YF: Single cell gel/comet assay: Guidelines for in vitro and in vivo genetic toxicology testing. Environ Mol Mutagen 35: 206-221, 2000.

19. An J, Wang X, Guo P, Zhong $Y$, Zhang $X$ and $Y u ~ Z$ : Hexabromocyclododecane and polychlorinated biphenyls increase resistance of hepatocellular carcinoma cells to cisplatin through the phosphatidylinositol 3-kinase/protein kinase B pathway. Toxicol Lett 229: 265-272, 2014.

20. Mueller T, Voigt W, Simon H, Fruehauf A, Bulankin A, Grothey A and Schmoll HJ: Failure of activation of caspase-9 induces a higher threshold for apoptosis and cisplatin resistance in testicular cancer. Cancer Res 63: 513-521, 2003.

21. Okouoyo S, Herzer K, Ucur E, Mattern J, Krammer PH, Debatin KM and Herr I: Rescue of death receptor and mitochondrial apoptosis signaling in resistant human NSCLC in vivo. Int J Cancer 108: 580-587, 2004.

22. Yamaguchi T, Nakajima N,Nakamura I, Mashiba H, Kawashiro T, Ebara K, Ichimura E, Nishimura C, Okamoto K, Ichikawa $Y$ and Ichida T: Preclinical anticancer effects and toxicologic assessment of hepatic artery infusion of fine-powder cisplatin with lipiodol in vivo. Drug Discov Ther 7: 201-208, 2013.

23. Ellis PA, Norman A, Hill A, O'Brien ME, Nicolson M, Hickish T and Cunningham D: Epirubicin, cisplatin and infusional 5-fluorouracil (5-FU) (ECF) in hepatobiliary tumours. Eur J Cancer 31A: 1594-1598, 1995.

24. Pruefer FG, Lizarraga F, Maldonado V and Melendez-Zajgla J: Participation of Omi Htra2 serine-protease activity in the apoptosis induced by cisplatin on SW480 colon cancer cells. J Chemother 20: 348-354, 2008.

25. Stordal B and Davey M: Understanding cisplatin resistance using cellular models. IUBMB Life 59: 696-699, 2007.

26. Callegari E, Gramantieri L, Domenicali M, D'Abundo L, Sabbioni S and Negrini M: MicroRNAs in liver cancer: A model for investigating pathogenesis and novel therapeutic approaches. Cell Death Differ 22: 46-57, 2015.

27. Lan $\mathrm{H}, \mathrm{Lu} \mathrm{H}$, Wang $\mathrm{X}$ and Jin $\mathrm{H}$ : MicroRNAs as potential biomarkers in cancer: Opportunities and challenges. Biomed Res Int 2015: 125094, 2015.
28. Zhang K, Chen J, Zhou H, Chen Y, Zhi Y, Zhang B, Chen L, Chu X, Wang R and Zhang C: PU.1/microRNA-142-3p targets ATG5/ATG16L1 to inactivate autophagy and sensitize hepatocellular carcinoma cells to sorafenib. Cell Death Dis 9: 312, 2018.

29. Shao P, Qu WK, Wang CY, Tian Y, Ye ML, Sun DG, Sui JD, Wang LM, Fan R and Gao ZM: MicroRNA-205-5p regulates the chemotherapeutic resistance of hepatocellular carcinoma cells by targeting PTEN/JNK/ANXA3 pathway. Am J Transl Res 9: 4300-4307, 2017.

30. He H, Tian W, Chen H and Deng Y: MicroRNA-101 sensitizes hepatocellular carcinoma cells to doxorubicin-induced apoptosis via targeting Mcl-1. Mol Med Rep 13: 1923-1929, 2016.

31. Grandage VL, Gale RE, Linch DC and Khwaja A: PI3-kinase/Akt is constitutively active in primary acute myeloid leukaemia cells and regulates survival and chemoresistance via NF-kappaB, Mapkinase and p53 pathways. Leukemia 19: 586-594, 2005.

32. Pellegrino R, Calvisi DF, Neumann O, Kolluru V, Wesely J, Chen X, Wang C, Wuestefeld T, Ladu S, Elgohary N, et al: EEF1A2 inactivates p53 by way of PI3K/AKT/mTOR-dependent stabilization of MDM4 in hepatocellular carcinoma. Hepatology 59: 1886-1899, 2014.

33. Fang Y, Chai Z, Wang D, Kuang T, Wu W and Lou W: DNA-PKes deficiency sensitizes the human hepatoma HepG2 cells to cisplatin and 5-fluorouracil through suppression of the PI3K/Akt/NF- $\mathrm{B}$ pathway. Mol Cell Biochem 399: 269-278, 2015.

34. Birbach A, Gold P, Binder BR, Hofer E, de Martin R and Schmid JA: Signaling molecules of the NF-kappa B pathway shuttle constitutively between cytoplasm and nucleus. J Biol Chem 277: 10842-10851, 2002.

35. Erstad DJ and Cusack JC Jr: Targeting the NF- $\mathrm{KB}$ pathway in cancer therapy. Surg Oncol Clin N Am 22: 705-746, 2013.

36. Chen Q, Jin M, Yang F, Zhu J, Xiao Q and Zhang L: Matrix metalloproteinases: Inflammatory regulators of cell behaviors in vascular formation and remodeling. Mediators Inflamm 2013: 928315, 2013.

37. Ito Y, Kikuchi E, Tanaka N, Kosaka T, Suzuki E, Mizuno R, Shinojima T, Miyajima A, Umezawa K and Oya M: Down-regulation of NF kappa B activation is an effective therapeutic modality in acquired platinum-resistant bladder cancer. BMC Cancer 15: 324, 2015.

\footnotetext{
This work is licensed under a Creative Commons Attribution-NonCommercial-NoDerivatives 4.0 International (CC BY-NC-ND 4.0) License.
} 